\title{
Exploring the Role of Leisure in Immigrant Students' Lived and Embodied Experiences of Identity, Community, and Belonging Within Halifax, Nova Scotia
}

\author{
Giana C.L. Tomas, BSc \\ School of Health and Human Performance, Dalhousie University \\ https://doi.org/10.15273/hpj.v1i1.10583
}

\begin{abstract}
The Canadian government employs robust efforts to promote and prioritize immigration, as immigration significantly contributes to Canadian economy, population, and culture. As Canada continues to grow as a culturally and racially diverse society, it is necessary to explore and understand immigrants' lived and embodied experiences within community, their sense of identity, and feelings of belonging, as these phenomena can shape health and well-being. Leisure activities or experiences are understood to cultivate and promote self-expression, socialization, and wellness amidst and despite challenges related to resettlement as experienced by immigrants. While there is enough literature about adult immigrants' settlement experiences and the impacts of such experiences on physical, social, emotional, and mental health and well-being, immigrants attending post-secondary institutions are understudied, particularly in Atlantic Canada. Further, the role of leisure in cultivating a sense of identity and belonging is underdeveloped within these contexts. This proposed qualitative study attends to these gaps by exploring the role of leisure in the lived and embodied experiences of identity, community, and belonging as experienced by immigrants attending post-secondary institutions in Halifax, Nova Scotia, Canada. Guided by Merleau-Ponty's principles of embodiment and a transformative paradigm, this proposed study employs collagemaking, a creative, participatory method to engage participants and understand their experiences, amplify their voices, and potentially enrich their lives and well-being. Findings of this proposed study can inform policy and practice within post-secondary institutions, settlement services, and community centres, and can deepen our understanding of leisure's potential to contribute to immigrants' identity, belonging, and well-being.
\end{abstract}




\section{Exploring the Role of Leisure in Immigrant Students' Lived and Embodied Experiences of Identity, Community, and Belonging Within Halifax, Nova Scotia}

Immigration contributes to Canada's economy and population, but also to its identity as a multicultural society (Caidi et al., 2010; Reitz, 2009). While Canada benefits largely from immigration in these aspects, immigrants are likely to experience significant resettlement challenges like barriers related to language and communication and lack of social supports, which can threaten their social, emotional, and mental health and well-being (Halli \& Anchan, 2005; Tsai \& Thompson, 2013; Vahabi \& Wong, 2017). Such challenges brought about by change and transition can also lead to social exclusion, isolation, or disconnection from culture or society (Hilario et al., 2015). Thus, immigrants' sense of identity and feelings of community and belonging (Gallant \& Tirone, 2017; George \& Selimos, 2019) are worth examining. As past research about immigrants' lived experiences in Canada has broadly linked resettlement experiences to immigrants' health and wellbeing (e.g., Asanin \& Wilson, 2008; Hilario et al., 2015), it is imperative to understand how such experiences can also shape immigrants' sense of identity and feelings of belonging within community.

Immigrant youth, ages 15 to 24 (Guruge \& Butt, 2015), are increasingly attending university upon resettlement in Canada (Childs et al., 2017) as higher education is associated with greater opportunities for experiencing social and economic integration (WilsonForsberg, 2015; Woodgate \& Busolo, 2018). In addition, post-secondary institutions can be sites for immigrant students to experience social support (Gagné et al., 2014) and feelings of inclusion and belonging (Selimos \& Daniel, 2017). However, immigrant students are more likely than Canadian-born students to experience shifts in their identity and sense of belonging due to challenges that accompany resettlement and migration (Hilario et al., 2015; Woodgate \& Busolo, 2018). It is thus necessary to explore immigrant students' experiences within these contexts as immigrants attending post-secondary institutions can experience intense shifts in their identity, as well as social isolation within and beyond school (Selimos \& Daniel, 2017; Sica et al., 2014).

Evidence about leisure's role in cultivating identity and a sense of community and belonging among immigrant students attending post-secondary institutions in Atlantic Canada is underdeveloped. Leisure activities or experiences are understood as any freelychosen activities (e.g., sports, art, or volunteering) that people engage in during their free time or time outside of their obligations, and are understood to provide them with opportunities to experience enjoyment, selfexpression, and/or socialization (Caldwell, 2005; Iwasaki \& Schneider, 2003; Karlis et al., 2002; Spracklen et al., 2015). Leisure can also have rehabilitative effects for immigrants experiencing isolation or disconnection, as engaging in leisure can foster or rebuild a sense of normalcy for people who have experienced change or disruption (Hurly \& Walker, 2019). Thus, a deeper exploration of the role of leisure in immigrant students' identity, community, and belonging within post-secondary institutions in Atlantic Canada is warranted.

\section{Proposed Study}

Leisure plays a key role in facilitating the development of one's identity and feelings of belonging, as engaging in leisure through different domains in one's life such as in community (Kelly \& Godbey, 1992; Liu \& Fu, 2019) can provide people with opportunities to further develop their sense of identity and feelings of belonging (Blackshaw, 2010; Spracklen et al., 2015). Thus, immigrant students' experiences of leisure can serve as a means for developing or enhancing their identity and feelings of belonging within a new community. This qualitative transformative study aims to explore leisure's role in cultivating a sense of identity, community, and belonging as experienced by immigrants attending postsecondary institutions in Halifax, Nova Scotia. Merleau-Ponty's principles of embodiment 
guide this study to understand lived and embodied experiences (Alcoff, 2006, Chapter 7; van Manen, 2014). A transformative paradigm is employed to actively engage participants through a collaborative and creative participatory data collection method, collagemaking (Vacchelli, 2018), to amplify participants' voices, raise concerns, and, hopefully, enrich their lives and well-being (Creswell \& Poth, 2018). Focus groups will subsequently be conducted to more deeply explore the memories, thoughts, and feelings elicited in the process and product of collagemaking, specifically their experiences of leisure, identity, and belonging (Creswell \& Poth, 2018; Vacchelli, 2018). Recordings from focus groups will then be transcribed and analyzed in conjunction with the collages.

\section{Significance}

Study findings can contribute to the literature about whether leisure experiences during postsecondary studies contribute to identity and feelings of belonging, and these can consequently assist faculty and university board members and community service providers in more deeply understanding immigrants' broader experiences of health and well-being. New knowledge from this study can also deepen our understanding of how leisure might contribute to immigrant students' resettlement experiences. Finally, new knowledge from this study can enhance the development of appropriate programs or services to support immigrant students' learning experiences and their overall health and well-being.

\section{References}

Alcoff, L. M. (2006). Visible identities: Race, gender, and the self. Oxford Scholarship Online.

https://doi.org/10.1093/0195137345. 001.0001

Asanin, J., \& Wilson, K. (2008). "I spent nine years looking for a doctor": Exploring access to health care among immigrants in Mississauga, Ontario, Canada. Social Science \& Medicine, 66(6), 1271-1283. https://doi.org/10.1016/j.socscimed.20 07.11.043

Blackshaw, T. (2010). Leisure. Routledge.

Caidi, N., Allard, D., \& Quirke, L. (2010). Information practices of immigrants. Annual Review of Information Science and Technology, 44(1), 491-531. https://doi.org/10.1002/aris.2010.144 0440118

Caldwell, L. L. (2005). Leisure and health: Why is leisure therapeutic? British Journal of Guidance and Counselling, 33(1), 7-26. https://doi.org/10.1080/03069880412 331335939

Childs, S., Finnie, R., \& Mueller, R. E. (2017). Why do so many children of immigrants attend university? Evidence for Canada. Journal of International Migration and Integration, 18(1), 1-28. https://doi.org/10.1007/s12134-0150447-8

Creswell, J. W., \& Poth, C.N. (2018). Qualitative inquiry and research design: Choosing among five approaches ( $4^{\text {th }}$ ed.). Sage.

Gallant, K., \& Tirone, S. (2017). A 'good life without bells and whistles': A case study of immigrants' well-being and leisure and its roles in social sustainability in Truro, Nova Scotia. Leisure/Loisir, 41(3), 423-442. https://doi.org/10.1080/14927713.20 17.1352456

Gagné, M. H., Shapka, J. D., \& Law, D. M. (2014). Moving beyond grades: The social and emotional well-being of Chinese Canadians at school. Asian American Journal of Psychology, 5(4), 373-382. https://doi.org/10.1037/a0038243

George, G., \& Selimos, E. D. (2019). Searching for belonging and confronting exclusion: A person-centred approach to immigrant settlement experiences in 
Canada. Social Identities, 25(2), 125140.

https://doi.org/10.1080/13504630.20 17.1381834

Guruge, S., \& Butt, H. (2015). A scoping review of mental health issues and concerns among immigrant and refugee youth in Canada: Looking back, moving forward. Canadian Journal of Public Health, 106(2), e72-e78. https://doi.org/10.17269/CJPH.106.45 88

Halli, S. S., \& Anchan, J. P. (2005) Structural and behavioural determinants of immigrant and non-immigrant health status:

Results from the Canadian Community Health Survey. Journal of International Migration and Integration, 6(1), 93-123. https://doi.org/10.1007/s12134-0051004-7

Hilario, C. T., Oliffe, J. L., Pui-Hing Wong, J., Browne, A. J., \& Johnson, J. L. (2015). Migration and young people's mental health in Canada: A scoping review. Journal of Mental Health, 24(6), 414422.

https://doi.org/10.3109/09638237.20 15.1078881

Hurly, J., \& Walker, G. J. (2019). "When you see nature, nature give you something inside": The role of nature-based leisure in fostering refugee well-being in Canada. Leisure Sciences, 41(4), 260277. https://doi.org/10.1080/01490400.20 17.1325799

Iwasaki, Y., \& Schneider, I. E. (2003). Leisure, stress, and coping: An evolving area of inquiry. Leisure Sciences, 25(2-3), 107113.

https://doi.org/10.1080/01490400306 567

Karlis, G., Grafanaki, S., \& Abbas, J. (2002). Leisure and spirituality: A theoretical model. Society and Leisure, 25(1), 205214. https://doi.org/10.1080/07053436.20 02.10707584

Kelly, J. R., \& Godbey, G. (1992). The sociology of leisure. Venture Publishing.

Liu, H.. \& Fu, J. (2019). Religious leisure, heritage and identity construction - A case of Tibetan college students. Leisure Studies, 38(5), 603-617. https://doi.org/10.1080/02614367.20 19.1597149

Reitz, J. G. (2009). Assessing multiculturalism as a behavioural theory. In J. G. Reitz, R. Breton, K. K. Dion, \& K. L. Dion (Eds). Multiculturalism and social cohesion: Potentials and challenges of diversity. (pp. 1-47). Springer. http://dx.doi.org/10.1007/978-14020-9958-8

Selimos, E. D., \& Daniel, Y. (2017). The role of schools in shaping the settlement experiences of newcomer immigrant and refugee youth. International Journal of Child, Youth \& Family Studies, 8(2), 90-109. http://dx.doi.org/10.18357/ijcyfs8220 1717878

Sica, L. S., Sesito, L. A., \& Ragozini, G. (2014). Identity coping in the first years of university: identity diffusion, adjustment and identity distress. Journal of Adult Development, 21(3), 159-172. https://doi.org/10.1007/s10804-0149188-8

Spracklen, K., Long, J., \& Hylton, K. (2015). Leisure opportunities and new migrant communities: Challenging the contribution of sport. Leisure Studies, 34(1), 114-129. https://doi.org/10.1080/02614367.20 14.939989

Tsai, J. H., \& Thompson, E. A. (2013). Impact of social discrimination, job concerns, and social support on Filipino immigrant worker mental health and substance 
use. American Journal of Industrial

Medicine, 56(9), 1082-1094.

https://doi.org/10.1002/ajim.22223

Vacchelli, E. (2018). Embodiment in qualitative research: Collage making with migrant, refugee and asylum seeking women. Qualitative Research, 18(2), 171-190. https://doi.org/10.1177/14687941177 08008

Vahabi, M., \& Wong, J. P. (2017). Caught between a rock and a hard place: Mental health of migrant live-in caregivers in Canada. BMC Public Health, 17(1), Article 498. https://doi.org/10.1186/s12889-0174431-4

van Manen, M. (2014). Phenomenology of practice: Meaning-giving methods in phenomenological research and writing. Left Coast Press.

Wilson-Forsberg, S. (2015). "We don't integrate; we adapt:" Latin American immigrants interpret their Canadian employment experiences in Southwestern Ontario. Journal of International Migration and Integration, 16(3), 469-489.

https://doi.org/10.1007/s12134-0140349-1

Woodgate, R. L., \& Busolo, D. S. (2018). Above chaos, quest, and restitution: Narrative experiences of African immigrant youth's settlement in Canada. $B M C$ Public Health, 18(1), Article 333. https://doi.org/10.1186/s12889-0185239-6 